\title{
Adoption of continuous wavelet and recurrence plots to comparative studies of neutron monitor data sets from the period $1975-1992$
}

\section{Tomasz Seredyn ${ }^{1}$}

Polish Air Force Academy,

Deblin, Poland

E-mail: t.seredyn@law.mil.pl

\section{Arkadiusz Wysokinski}

Independent researcher

Iganie, Poland

E-mail: arekwysetlen.pl

\section{Zbigniew Kobylinski}

High School of National Economics in Kutno

Kutno, Poland

E-mail: zbigniewkobylinski@yahoo.com

\section{Abstract}

The hourly pressure corrected data of individual neutron monitor station (NM) collected in WDC, from seventies of XX century to nowadays, are compared with records of other stations with similar cut-off rigidity in order to determine the quality of the studied data. Taking no account some short time details as GLE events, one can expect a similar NM intensity response at stations, with the similar cut-off rigidity, to the solar variability on moderate and long time scales. It could be reflected by similar values of the Pearson correlation coefficients and slopes of regression lines between the smoothed solar activity indices and NM data. The solar activity is represented by Ottawa/Penticon radio flux. If the correlation coefficients considerably wander away from the mean value for the determined epoch the data registered at such station in this time period should not be used to a further study of long-term variations. Powerful wavelet technique can also is applied to test the data in time - frequency space. We 
provide such analysis for two sets of data with high and moderate cut-off rigidities. Periods with data gaps or with inconsistency of records ought to be corrected before further elaboration by means of the neuron network (NN) reconstructions. We propose the Elman NN as possibly the best available method for such correction. The results are presented in tables and on wavelet plots. Stations which have showed considerably different variations at some periods than other are indicated.

\section{Introduction}

Many time series of neutron component data are collected in World Data Centers from the fifties of $20^{\text {th }}$ century to nowadays. It is very important to believe that those data are typified as stabilized and generally of a good quality. In the prepared paper the correctness of the pressure corrected data of individual neutron monitor (NM) stations is examined on the monthly to yearly time scale separately for the periods of different heliospheric magnetic field polarity from 1958 to 2014. Taking no account some short time details as GLE events, one can expect a similar NM intensity response at every station with the similar cut-off rigidity, and possibly if such stations exist with similar asymptotic directions, to the solar variability on moderate and long time scales. It could be reflected by similar values of the Pearson correlation coefficients and slopes of regression lines between the smoothed solar activity indices and NM data registered at different stations. The solar activity is represented by Ottawa/Penticon radio flux. If the correlation coefficients considerably wander away from the mean value for the determined epoch the data registered at such station in that time period should not be used to a further study of long-term variations. Powerful wavelet technique can also be applied to test in time - frequency space the existing data. As examples, we show in this poster such the preliminary study of variability of 3 neutron monitor stations: Rome, Alma Ata B and Tbilisi in the time period 1975-1992.

\section{Data used}

We use here the hourly pressure corrected data from 3 neutron monitor stations with cut off rigidities equal about $6 \mathrm{GV}$ as it is shown on Table 1. Only a few stations with this value of cut off exist. The knowledge of cosmic ray particle variations of rigidities equal and bigger than $6 \mathrm{GV}$ is very important for modulation theories. The 
source of the data: World Data Center for Cosmic Rays, Solar-Terrestrial Environment Laboratory, Nagoya University (ftp://ftp.stelab.nagoya-u.ac.jp/pub/WDCCR/STATIONS).

Table 1. NM stations

\begin{tabular}{|l|c|c|c|c|c|c|c|}
\hline NM station & Station ID & instrument & $\begin{array}{c}\text { geog. latit. } \\
(\mathrm{deg} .) .\end{array}$ & $\begin{array}{c}\text { geog. long. } \\
(\mathrm{deg} .)\end{array}$ & $\begin{array}{c}\text { Cut-Off } \\
\text { Rigidity } \\
\text { (GV) }\end{array}$ & $\begin{array}{c}\text { Altitud } \\
\text { e (m) }\end{array}$ & time period \\
\hline Rome & ROME & $\begin{array}{c}\text { 9-NM-64 } \\
\text { 12-NM-64 } \\
\text { 17-NM-64 }\end{array}$ & 41.90 & 12.52 & 6.24 & 60 & $\begin{array}{c}1975-1980 \\
1981-1984 \\
1985-1992\end{array}$ \\
\hline Alma Ata B & ALMA B & $18-N M-64$ & 43.25 & 76.92 & 6.61 & 3340 & $1975-1992$ \\
\hline Tbilisi & TBILIS & $18-N M-64$ & 41.72 & 44.80 & 6.66 & 510 & $1975-1991$ \\
\hline
\end{tabular}

As the basic level of original tabular hourly Rome data was changed after 1 Jan 1984, so we have improved them by multiplying the data from the period $1975-1984$ by the factor 1,9298. Three time series are shown in Fig. 1

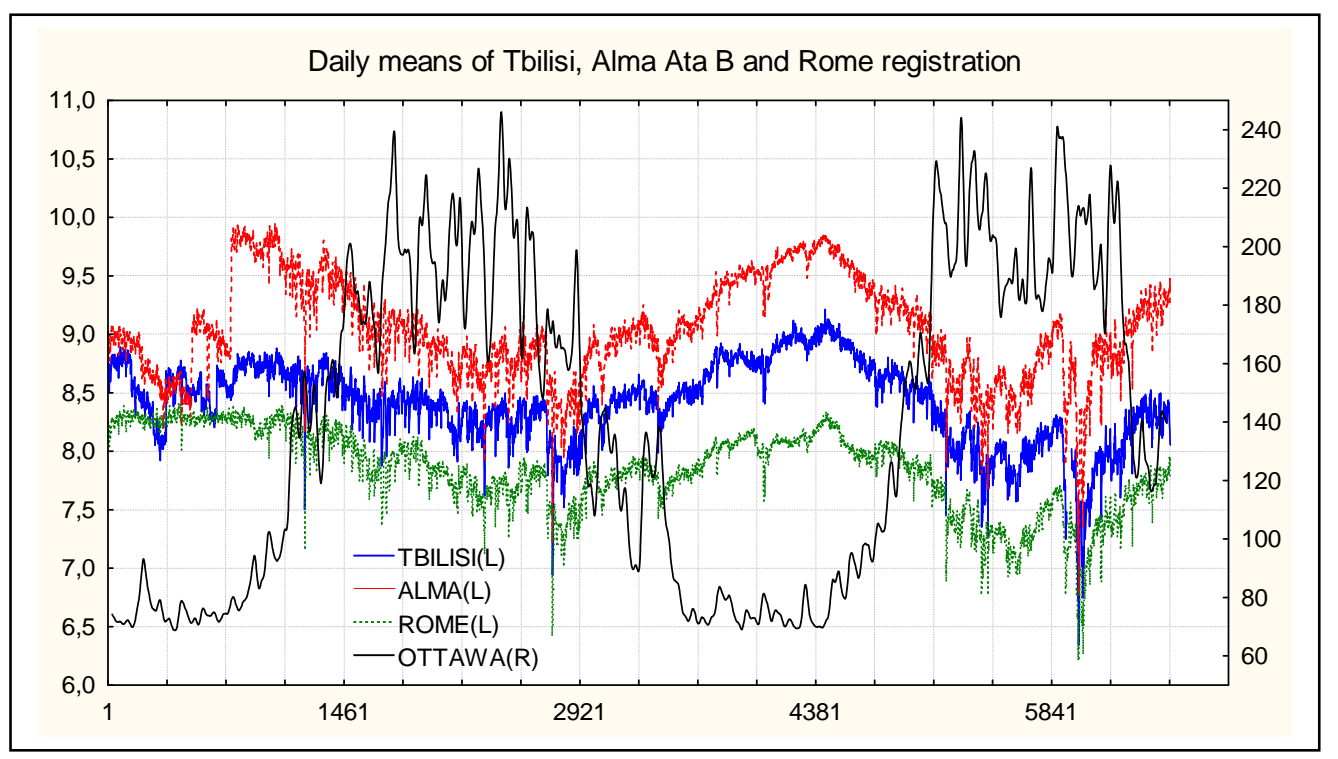

Fig. 1

In Fig. 1 the $24^{\text {th }}$ - point moving means of Ottawa/Penticon radio flux are plotted as measure of the solar activity. Every data of NM stations has been divided by 1000 , for the clarity of the Rome records were multiplied by 1.43. For further analysis rather small effects of GLE's in the NM records (GLEs $\mathrm{nr} 27$ to 53) in above mentioned ranges of rigidities have been excluded and the gaps in data were filled up by means of interpolation. 
Table 2: quality of hourly data collected in WDC CR (1975-92): number of:

\begin{tabular}{|l|c|c|c|c|c|}
\hline NM station & gaps $\leq 6^{\mathrm{h}}$ & $6^{\mathrm{h}} \leq 1^{\mathrm{d}} \mathrm{t}$ & $1^{\mathrm{d}} \leq 15^{\mathrm{d}}$ & $15^{\mathrm{d}}>$ & $\begin{array}{c}\text { baseline } \\
\text { incorrectness }\end{array}$ \\
\hline Rome & 36 & 5 & - & - & 1 \\
\hline Alma Ata B & 23 & 40 & 18 & - & 2 \\
\hline Tbilisi & 234 & 114 & 36 & 1 & 1 \\
\hline
\end{tabular}

\section{Methods of data analysis}

We apply correlative analysis, wavelet technique and recurrence plots which lets to estimate the coherence between analyzed data. The magnitude-squared coherence between two time series $x(t)$ and $y(t)$ at the frequency $\omega$ is defined as

$$
\mathrm{C}_{\mathrm{xy}}{ }^{2}(\omega)=\left|\mathrm{P}_{\mathrm{xy}}(\omega)\right|^{2} / \mathrm{P}_{\mathrm{xx}}(\omega) \mathrm{P}_{\mathrm{yy}}(\omega)
$$

where $t$ is time, $P_{x x}$ and $P_{y y}$ are power spectral densities of the series, $P_{x y}$ is the cross spectral density between these time series ${ }^{2}$. The wavelet transform describes filtration of an analyzed signal $x(t)$ using real or complex-valued function $\psi(t, a)$, which is defined as

$$
\left.\mathrm{W}_{\mathrm{x}}(\mathrm{t}, \mathrm{a})=\left(1 / \mathrm{a}^{-0.5}\right) \int \psi^{*}(\tau-\mathrm{t}) / \mathrm{a}\right) \cdot \mathrm{x}(\tau) \mathrm{d} \tau
$$

where * denotes complex conjugate, variable $a$ and $\tau$ are the dilation (frequency) and translation (position) scaling factors. In the case of one-dimensional original signal, the continuous wavelet transform generates a two-dimensional picture of the wavelet power (scalogram) ${ }^{3}$ :

$$
S_{x}(t, a)=\left|W_{x}(t, a)\right|^{2}
$$

The cross wavelet transform of two time series $\mathrm{x}$ and $\mathrm{y}$ is defined as

$$
\mathrm{S}_{\mathrm{xy}}(\mathrm{t}, \mathrm{a})=\mathrm{W}_{\mathrm{x}}(\mathrm{t}, \mathrm{a}) \mathrm{W}_{\mathrm{y}}(\mathrm{t}, \mathrm{a}),
$$

the wavelet coherence (WTC) of two signals or time series is defined as

$$
\mathrm{C}_{\mathrm{xy}}{ }^{2}(\mathrm{t}, \mathrm{a})=\left|\mathrm{A}\left(\mathrm{a}^{-1} \mathrm{~S}_{\mathrm{xy}}(\mathrm{t}, \mathrm{a})\right)\right|^{2} /\left(\mathrm{A}\left(\mathrm{a}^{-1}\left|\mathrm{~S}_{\mathrm{x}}(\mathrm{t}, \mathrm{a})\right|\right) \cdot \mathrm{A}\left(\mathrm{a}^{-1}\left|\mathrm{~S}_{\mathrm{y}}(\mathrm{t}, \mathrm{a})\right|\right)\right),
$$

where $A$ is a smoothing operator along time axis and scale axis. It is a complex function and is resembled the formula for correlation coefficient, $0 \leq \mathrm{C}_{x y}{ }^{2}(t, a) \leq 1$. When coherence values for two time series are close to one it can be concluded that both data sets are very similar in a wide range of frequencies. In the paper we use the

\footnotetext{
2 Otnes R.K., Enochson L. Digital Time Series Analysis. J. Wiley \& Sons, New York, 1972.

Daubechies I. Ten lectures on wavelets, SIAM, Philadelphia, 1992.
} 
packages prepared by Torrence \& Compo ${ }^{4}$, Grinsted et al. ${ }^{5}$, and Rwave program ${ }^{6}$, which employs the Morlet wavelet in order to evaluate scalograms and WTC of two data sets

$$
\psi(\mathrm{t}, \mathrm{a})=\pi^{-1 / 4} \mathrm{e}^{\mathrm{i} \omega_{0} \eta} \mathrm{e}^{-\frac{1}{2} \eta^{2}},
$$

where $\omega_{0}$ is the dimensionless frequency, $\eta$ is the dimensionless time.

Recurrent analysis was originally proposed by Eckmann et al. ${ }^{7}$ as a graphical realization of the basic property of recurrence (repeatability of the trajectory of a dynamical system in the phase space). A recurrence plot (RP) is represented by a twodimensional square matrix with elements taking the values of zero and unity ${ }^{8}$

$$
R_{i, j}=\theta\left(\varepsilon_{\mathrm{i}}-\left|x_{i}-x_{j}\right|\right)
$$

where $\mathrm{i}, \mathrm{j},=1, \ldots, N$ is the number of $x_{i}$ states under consideration; $\varepsilon_{i}$ is the boundary distance parameter which denotes the density of recurrence points, $\theta$ is the the Heaviside function. If the state of a system at the time $i$ is recurrent to another state at the time $j$, , the corresponding element $(\mathrm{i}, \mathrm{j})$ of the recurrence matrix is unity, otherwise it is zero. On a recurrence plot, units are imaged by black dots, while zeros are imaged by white dots. Both the ordinate and abscissa axes of the recurrence plot represent the time.

Extension of RP is Cross-Recurrence Plot (CRP). In this case two time series $(i=$ $\left.1, \ldots, N_{x}\right)\left(j=1, \ldots, N_{y}\right)$ are considered in the same phase space. Commonly $N_{x} \neq N_{y}$, then CRP is non-square matrix. Depending on kind of relationships between time series the main diagonal can be broken, curved or even vanished. In special case when $x=y$, the main diagonal is the line of synchronization (LOS).

\footnotetext{
Torrence C., Compo G.P. A practical guide to wavelet analysis. Bull. Amer. Meteor. Soc., 79, pp. 61-78, 1998, (http://paos.colorado.edu/research/wavelets/)

Grinsted A., J.C. Moore, S. Jevrejeva (2004). Application of the cross wavelet transform and wavelet coherence to geophysical time series. Nonlin. Proc. Geophys., v. 11, 561-566. (http://www.pol.ac.uk/home/research/waveletcoherence)

Carmona R., Hwang W.L., Torresani B. Practical Time-Frequency Analysis: Gabor and Wavelet Transforms with an Implementation in S. Academic Press, 1998. (http://cran.r-project.org/web/ packages/Rwave/; (http://r-forge.r-project.org/projects/rwave)

Eckmann J.P., Kamphorst S.O., Ruelle D. Recurrence plots of dynamical systems. Europhysics Letters, vol. 5 (9), pp. 973-977, 1987. 8

Marwan N., Romano M.C., Thiel M., Kurts J. Recurrence plots for the analysis of complex systems. Physics reports, vol. 438(5-6), pp. 237-329, 2007.
} 
Adoption of continous wavelet and reccurence plots to comparative studies of neutron monitor data sets from the period 1975-1992

$$
C R_{i, j}=\theta\left(\varepsilon_{i}-\left|x_{i}-x_{j}\right|\right), \quad i, j=1, \ldots, N
$$

Construction of the cross recurrence plot implies the analysis of two time series rather than one.

The presence of diagonal structures (in the simplest case, lines) on the recurrence or cross recurrence plot is evidence of a synchronous evolution of the processes under consideration.

Table 3. Pearson correlation coefficients */

\begin{tabular}{|l|c|c|c|c|c|c|c|c|c|c|c|c|c|}
\hline & \multicolumn{3}{|c|}{ whole period } & \multicolumn{3}{c|}{$1975-1980$} & \multicolumn{3}{c|}{$1980-1986$} & \multicolumn{2}{c|}{$1986-1989$} \\
\hline & $\begin{array}{c}\text { Daily } \\
\text { means }\end{array}$ & no & $\begin{array}{c}\text { Bartels } \\
\text { rotation } \\
\text { means }\end{array}$ & $\begin{array}{c}\text { Daily } \\
\text { means }\end{array}$ & $\begin{array}{c}\text { Bartels } \\
\text { rotation } \\
\text { means }\end{array}$ & $\mathrm{n}$ & $\begin{array}{c}\text { Daily } \\
\text { means }\end{array}$ & $\mathrm{n}$ & $\begin{array}{c}\text { Bartels } \\
\text { rotation } \\
\text { means }\end{array}$ & $\begin{array}{c}\text { Daily } \\
\text { means }\end{array}$ & $\begin{array}{c}\text { Bartels } \\
\text { rotation } \\
\text { means }\end{array}$ \\
\hline Ottawa - Rome & -0.67 & 6520 & -0.73 & -0.79 & -0.81 & 214 & -0.63 & 2166 & -0.78 & -0.82 & -0.83 \\
\hline Ottawa - Tbilisi & -0.67 & 6316 & -0.73 & -0.34 & -0.39 & 201 & -0.71 & 2166 & -0.79 & -0.88 & -0.89 \\
\hline Ottawa - Alma Ata & -0.51 & 6520 & -0.63 & -0.16 & -0.20 & 214 & -0.71 & 2166 & -0.76 & -0.87 & -0.88 \\
\hline Rome - Tbilisi & 0.80 & 6312 & 0.76 & 0.30 & 0.34 & 199 & 0.81 & 2166 & 0.90 & 0.91 & 0.92 \\
\hline Rome - Alma Ata & 0.70 & 6540 & 0.83 & 0.15 & 0.20 & 201 & 0.80 & 2166 & 0.90 & 0.94 & 0.96 \\
\hline Alma Ata - Tbilisi & 0.80 & 0.85 & 6312 & 0.58 & 0.93 & 190 & 0.81 & 2165 & 0.91 & 0.95 & 0.96 \\
\hline
\end{tabular}

*/ All coefficients have a significance level $\mathrm{p}<0.05, \mathrm{n}$ - number of daily values used

For the first selected period: 1975-1980 the correlation between NM stations is rather weak, also it is seen from Fig. 1. It is seen that the station Rome well correlated with solar activity. The longer and short term variability of the neutron monitor intensities during the period studied are seen from the scalograms of the $12^{\text {th }}$ hour means of data presented in Fig 2 and 3.5 where the variability of them is much better illustrated than through the simple correlation.
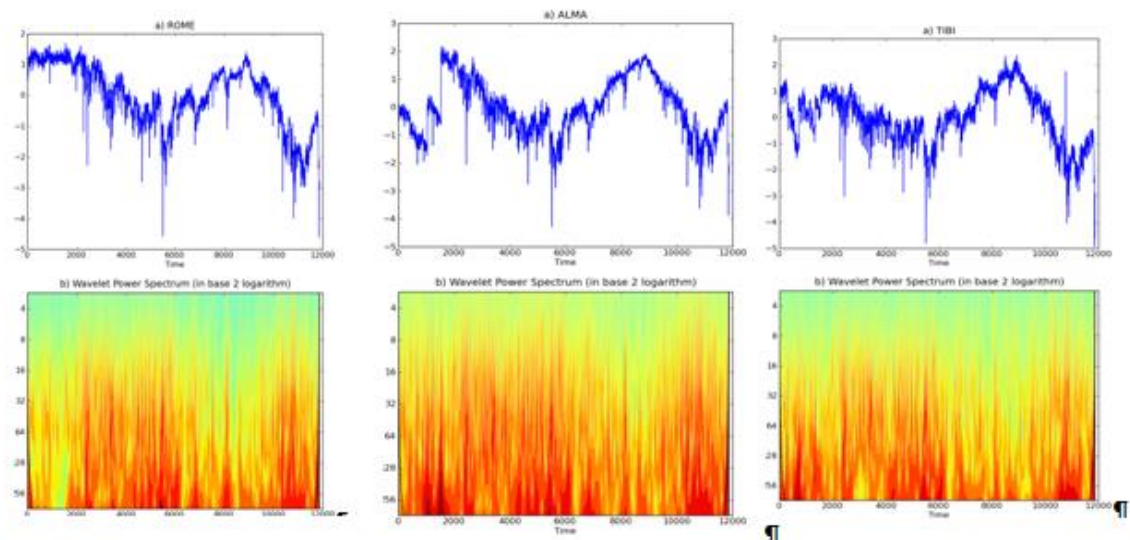

Fig. -2 -Wavelet scalograms of -12-hour-means-NM data from the stations: Rome, Alma-Ata, Tbilisin

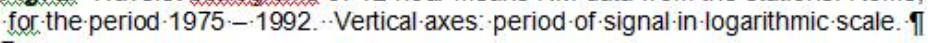




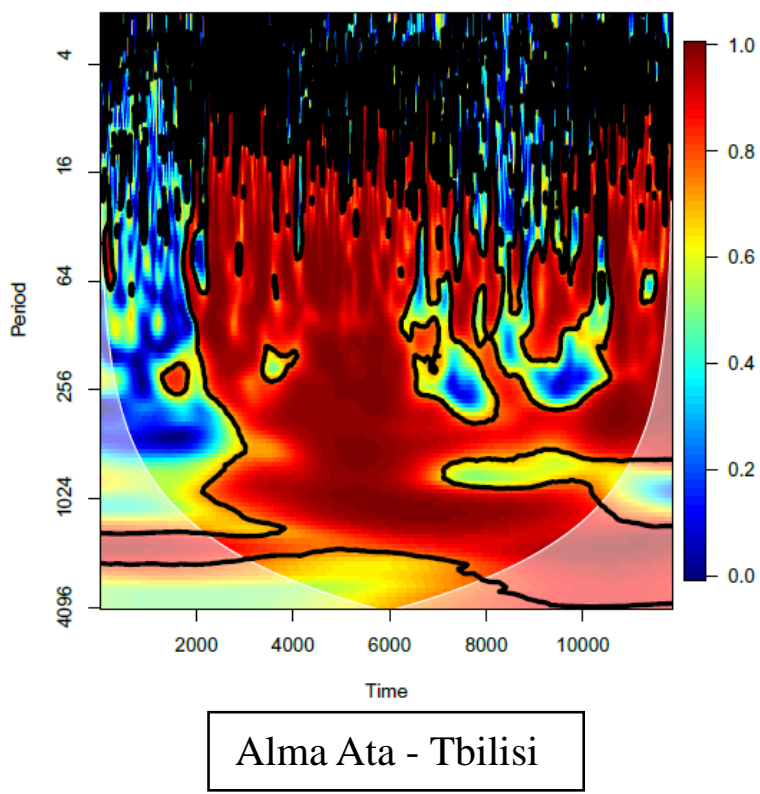

Fig. 3. Wavelet coherence between hour NM data during part of the mentioned period. Thick contours separate statistically significant regions (red, dark red) on the level of $95 \%$ against red noise and designate cones of influence of edge. Horizontal axis: 12 hour means, vertical axis: period of signal.

Dark red and red colors show the periods of good consistency between Alma Ata and Tbilisi data.

1

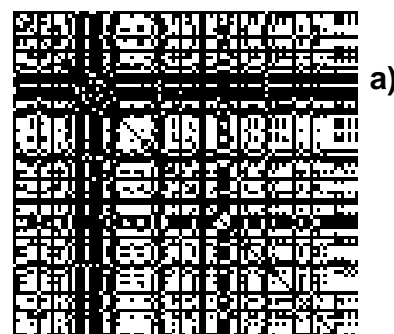

a)

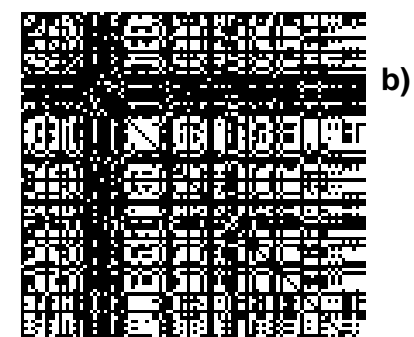

b)

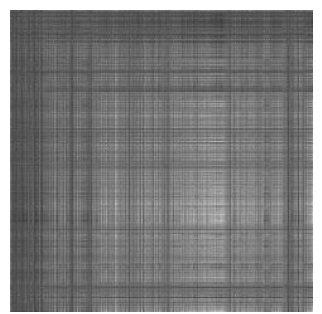

c)

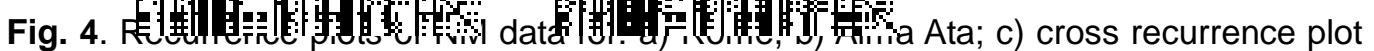
of two time series for these observatories. Vertical and horizontal axes: time in 12 hour means.

\section{Conclusions}

Wavelet technique and recurrence plots can be useful for comparisons showed above. From presented 3 stations Rome and Alma Ata are recommended for further work.

\section{References}

Carmona R., Hwang W.L., Torresani B. Practical Time-Frequency Analysis: Gabor and Wavelet Transforms with an Implementation in S. Academic Press, 1998.

Daubechies I. Ten lectures on wavelets, SIAM, Philadelphia, 1992.

Eckmann J.P., Kamphorst S.O., Ruelle D. Europhysics Letters, vol. 5 (9), 973-977, 1987.

Grinsted A., J.C. Moore, S. Jevrejeva (2004). Proc. Geophys., v. 11, 561-566.

Marwan N., Romano M.C., Thiel M., Kurts J. Physics reports, vol. 438 (5-6), 237-329, 2007

Otnes R.K., Enochson L. Digital Time Series Analysis. J. Wiley \& Sons, New York, 1972

Torrence C., Compo G.P. Bull. Amer. Meteor. Soc., 79, 61-78, 1998, 